Research Article

\title{
Flexural Behavior of Fiber-Reinforced Self-Stressing Concrete T-Shaped Composite Beams
}

\author{
Boxin Wang $(\mathbb{D}$, Ruichang Fang, and Qing Wang (iD \\ College of Construction Engineering, Jilin University, Changchun 130021, China \\ Correspondence should be addressed to Boxin Wang; boxinwang@jlu.edu.cn
}

Received 16 March 2020; Revised 6 May 2020; Accepted 20 May 2020; Published 24 June 2020

Academic Editor: Yifeng Ling

Copyright ( 2020 Boxin Wang et al. This is an open access article distributed under the Creative Commons Attribution License, which permits unrestricted use, distribution, and reproduction in any medium, provided the original work is properly cited.

\begin{abstract}
Given the excellent crack resistance performance of steel fiber-reinforced self-stressing concrete (SFRSSC), the bending performance of some composite beams with SFRSSC laminated layers was studied. The experiment conducted in this study comprised a single-span composite beam test (including 3 test beams) and a two-span continuous composite beam test (including 2 test beams). All the test beams were T-shaped. The cracking load, yielding load, and ultimate load of all the test beams were recorded and comparatively analyzed. Experimental results showed that the cracking load of the test beam with an SFRSSC laminated layer is significantly increased. Mechanical analysis and numerical simulation of the test beams were conducted, and the obtained results agreed well with the experimental results. The composite beams under different working conditions were also numerically simulated. Through the simulation, reasonable ranges of precompressive stress and length of the SFRSSC laminated layer at intermediate support of continuous composite beam were obtained.
\end{abstract}

\section{Introduction}

As an important part of a bridge, a bridge deck pavement can protect road plates from direct wheel abrasion and the main girder from erosion by rain and other harmful substances. Furthermore, vehicle load is dispersed by deck pavement. Cement concrete and asphalt concrete are widely used for deck pavement, and these concrete types can meet the standard requirement [1]. When the deck pavement cracks, the main girders of the bridge will be exposed to the natural environment, affecting the normal service and durability of the bridge structure [2-5]. Thus, experts from China and other countries have conducted various studies on bridge deck pavement in recent years. Ultra-high-performance fiber-reinforced concrete (UHPFRC) [6-20], microexpansion polypropylene fiber concrete [21], ECC [22, 23], steel fiber polymer concrete [24-26], and other special materials have been introduced and studied for bridge deck pavement.

During the hardening process of steel fiber-reinforced self-stressing concrete (SFRSSC), the expansion of selfstressing concrete is limited by steel, steel fibers, and other constraint surfaces. A certain chemical precompressive stress generated in the concrete enhances the crack resistance of concrete. The concrete in the support area of the continuous concrete bridge easily cracks because of the negative moment. Given the excellent crack resistance performance of SFRSSC, the bending performance of some composite beams, which have SFRSSC laminated layers, was investigated in this study. The experiment included a singlespan composite beam test and a two-span continuous composite beam test. All of the test beams were T-shaped. Furthermore, properties of the composite beams under different conditions were studied by numerical simulation. Different self-stress values and lengths of SFRSSC laminated layer were taken into account. The conclusion could provide a reference for the design of SFRSSC deck pavement.

\section{Materials and Properties}

2.1. Materials. Two kinds of cement are used in the experiment, Portland cement P.O. 32.5R for ordinary concrete (C) and steel fiber reinforced concrete (SFRC) and sulfur aluminate cement 4.0 for SFRSSC. The aggregate was composed of limestone with particle diameters ranging from 
$5 \mathrm{~mm}$ to $20 \mathrm{~mm}$ and high-quality river sand. The grading curves of the stone and sand are showed in Figures 1 and 2, respectively. The type of steel fiber used in the experiment was HE $0.75 / 35$. The properties of the steel fiber are shown in Table 1 . The yield strength of the reinforcement used in the test was $335 \mathrm{MPa}$, and the yield strength of the stirrup was $300 \mathrm{MPa}$. The tensile strength, ultimate elongation, and yield strength of reinforcement with different diameters were measured by a material mechanics test. Six specimens were tested for each kind of reinforcement, and the results are shown in Table 2. All concrete specimens in the experiment were prepared with tap water. Sika ViscoCrete 3301 waterreducing agent was used in the experimental specimens to increase the workability of concrete.

2.2. Properties of Concrete. Three kinds of concrete were used in experiment, including ordinary concrete, SFRC, and SFRSSC. The mixture ratios for these three kinds of concrete are shown in Table 3. Cubic compressive strength $\left(f_{\mathrm{cu}}\right)$, axial compressive strength $\left(f_{c}\right)$, elastic modulus $\left(E_{c}\right)$, and splitting tensile strength $\left(f_{\mathrm{ts}}\right)$ were measured for each kind of concrete. Six specimens were prepared to test every property of each kind of concrete. Table 4 shows the test results.

\section{Experimental Investigation}

3.1. Test Setup. The test includes two parts. The first part is the single-span composite T-shaped beam test. Three test beams were fabricated to simulate the force condition of the bridge structure with SFRSSC as deck pavement. The deck pavement of three test beams used ordinary concrete, SFRC, or SFRSSC. In the first part, the influence of the SFRSSC deck pavement on the crack resistance and flexural properties of the test beams is mainly investigated. The second part is a two-span continuous composite T-shaped beam test. This part includes two test beams, separately decked with ordinary concrete and SFRSSC. In this part, the bridge structure with SFRSSC deck pavement is simulated, and its working performance is investigated. The details of test beams are presented in Figures 3-7.

3.2. Specimen Preparation. The basic T-shaped beams were cast with ready-mix concrete after finishing the mesh reinforcement (Figure 7). The specimens were left at room temperature and covered with wet straw matting for 28 days. Subsequently, the concrete laminated layer was poured after a chiseled concrete surface was attained (Figures 8 and 9). The beams were aged for another 28 days (Figure 10). The details of the test beams are presented in Tables 5 and 6 .

3.3. Test Program. For the single-span composite T-shaped beam test, beams were loaded with two concentrated loads (four-point bending scheme) which applied $1000 \mathrm{~mm}$ from the support (Figure 4). For the two-span continuous composite T-shaped beam test, beams were loaded with concentrated loads applied in the middle of every span. All the test loads were applied once. The experimental data

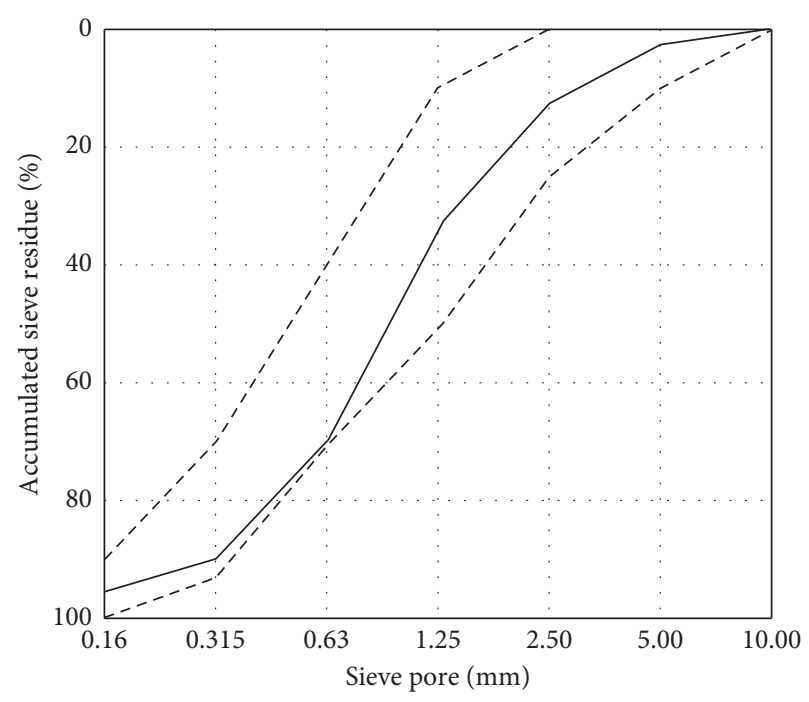

Figure 1: Grading curve of sand.

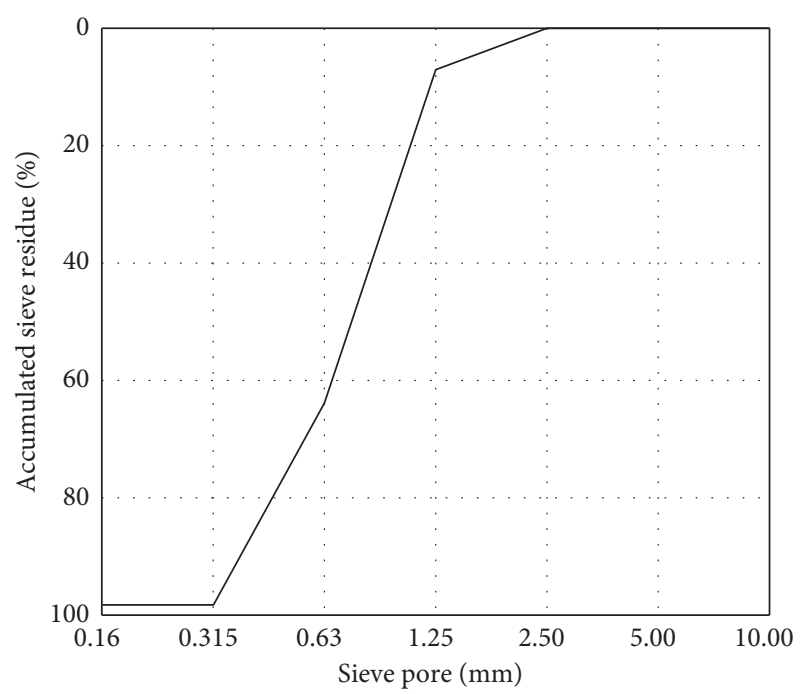

Figure 2: Grading curve of stone.

recorded during the test were as follows: cracking load, cracking deflection, ultimate bearing capacity, the strains of some special sections, deflection, crack width, and the relative slip between the laminated layer and the basic $\mathrm{T}$-shaped beams. The instruments used in the experiment and their locations are shown in Figures 4, 7, 10, and 11.

\section{Test Results}

\subsection{Single-Span Composite T-Shaped Beam Test Results}

4.1.1. Crack Development. All experimental beams suffered flexural failure. The concrete in the compressive area was crushed as the test beams failed (Figure 12). The tests showed that beam CCB-1 cracked first, followed by SCB-1 and ZCB1. As shown in Figure 13, the crack in CCB-1 developed faster than those in SCB-1 and ZCB-1 initially. However, when the test load reached $60 \mathrm{kN} \cdot \mathrm{m}$, the crack growth rate in SCB-1 suddenly accelerated, and the crack width 
TABLe 1: Properties of steel fiber.

\begin{tabular}{lcccc}
\hline Length $(\mathrm{mm})$ & Equivalent diameter $(\mathrm{mm})$ & Tensile strength $(\mathrm{MPa})$ & Ultimate elongation $(\%)$ & Elastic modulus $(\mathrm{GPa})$ \\
\hline 35 & 0.7 & 600 & 12 & 200
\end{tabular}

TABle 2: Properties of reinforcement.

\begin{tabular}{lcccc}
\hline Diameter $(\mathrm{mm})$ & Elastic modulus $(\mathrm{GPa})$ & Yield strength $(\mathrm{MPa})$ & Tensile strength $(\mathrm{MPa})$ & Ultimate elongation $(\%)$ \\
\hline 6.5 & 210 & 486.6 & 734.3 & 30 \\
8 & 210 & 306.5 & 444.9 & 31.6 \\
18 & 200 & 349.9 & 521.0 & 24.2 \\
20 & 200 & 377.4 & 571.1 & 24.5 \\
\hline
\end{tabular}

TABLe 3: Mixture ratios of different kinds of concrete $\left(\mathrm{kg} / \mathrm{m}^{3}\right)$.

\begin{tabular}{lcccccc}
\hline Concrete & Water & Cement & Sand & Stone & Sika3301 & Steel fiber \\
\hline C & 193 & 350 & 645.7 & 1133 & 6.50 & 0 \\
SFRC & 172 & 541 & 765 & 974 & 5.41 & 25.6 \\
SFRSSC & 250 & 550 & 609 & 913 & 8.25 & 23.3 \\
\hline
\end{tabular}

Table 4: Mechanical prosperities of concrete.

\begin{tabular}{lcccc}
\hline Concrete & $f_{\mathrm{cu}}(\mathrm{MPa})$ & $f_{c}(\mathrm{MPa})$ & $E_{c}(\mathrm{GPa})$ & $f_{\mathrm{ts}}(\mathrm{MPa})$ \\
\hline C & 48.7 & 45.2 & 33.5 & 3.5 \\
SFRC & 60.5 & 55.9 & 36.0 & 5.1 \\
SFRSSC & 59.9 & 52.0 & 33.4 & 5.2 \\
\hline
\end{tabular}

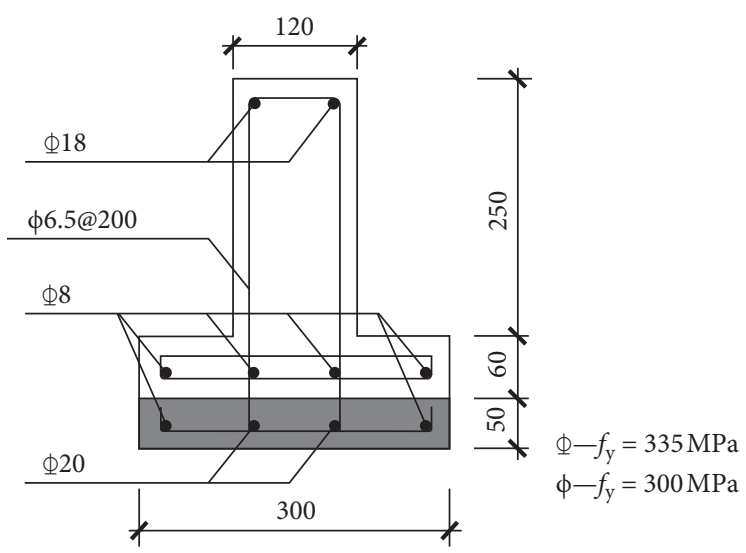

Figure 3: Reinforcement of single-span composite T-shaped beams.

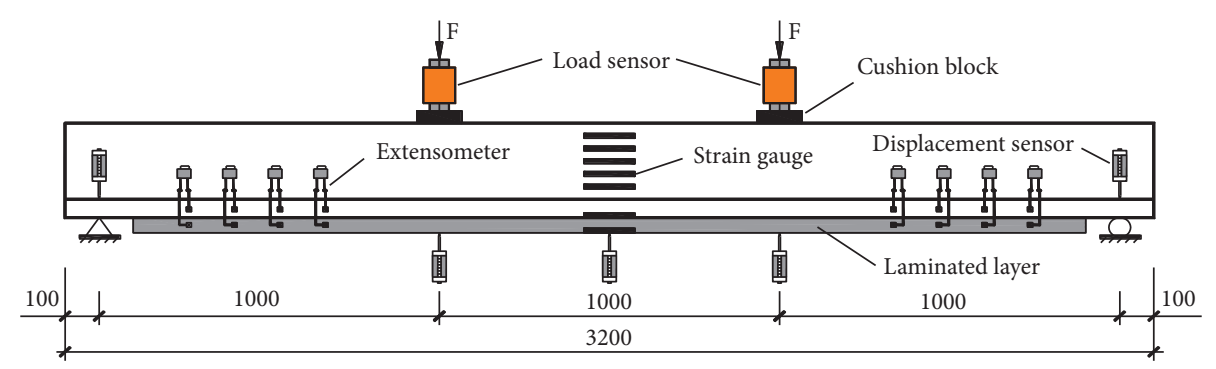

Figure 4: Details of single-span composite T-shaped beam test setup.

approached that in CCB-1. As the test beams started to yield, the crack width of CCB-1 reached $0.6 \mathrm{~mm}$, whereas the crack widths of SCB-1 and ZCB-1 were only $0.4 \mathrm{~mm}$ and $0.2 \mathrm{~mm}$, respectively. The development of the crack height in each of the three test beams is shown in Figure 14. As shown in Figure 14, the crack heights of the test beams developed at 


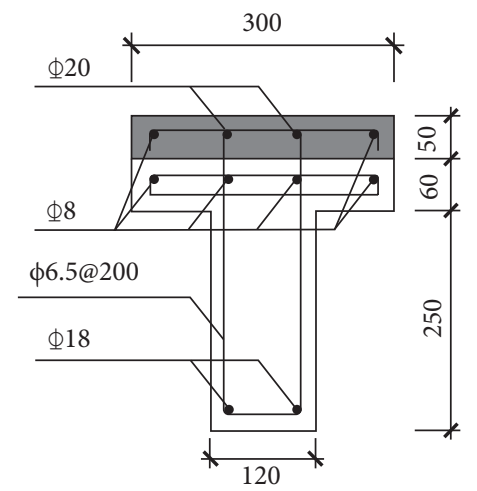

FIgURE 5: Reinforcement of the cross section at the middle support.

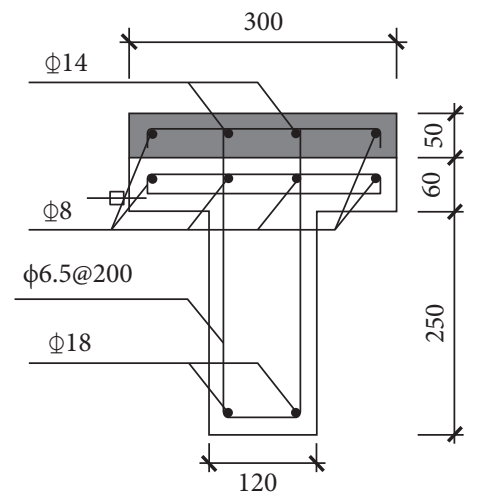

Figure 6: Reinforcement of the cross section at the midspan.

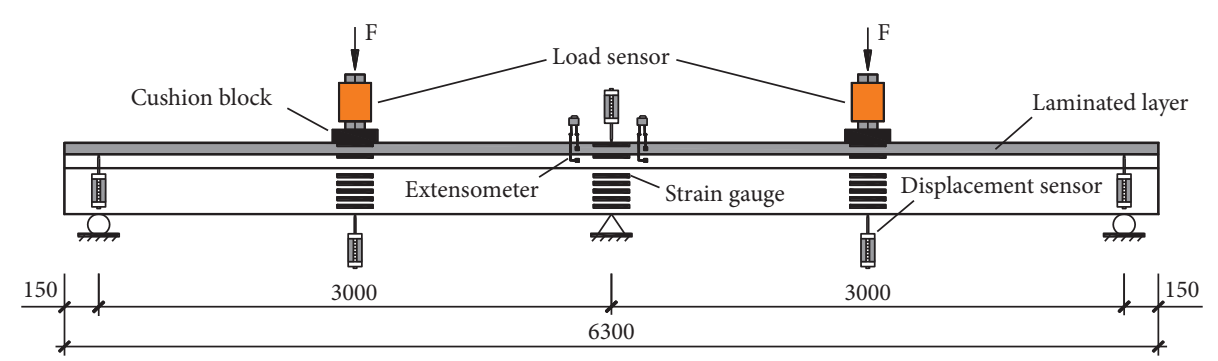

Figure 7: Details of the two-span continuous composite T-shaped beam test setup.

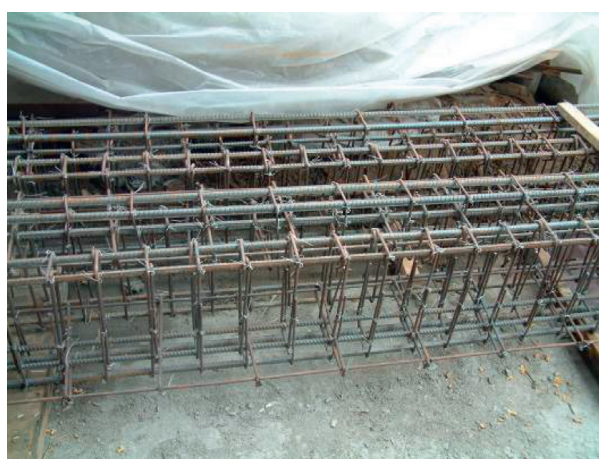

Figure 8: Bars. 


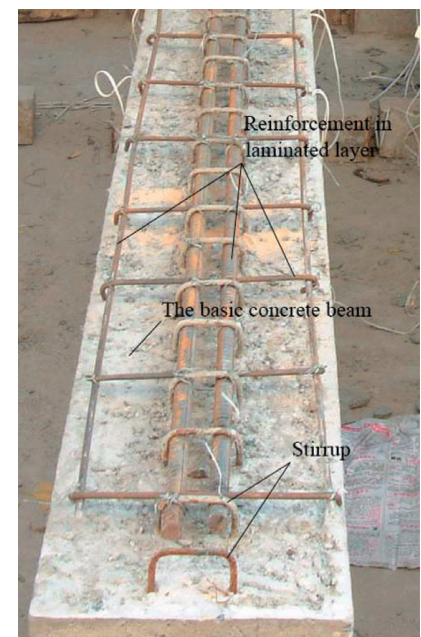

FIgURE 9: Chiseled basic T-shaped beams.

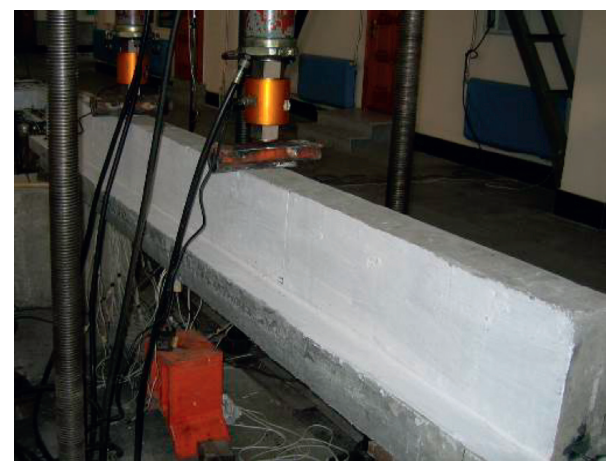

Figure 10: Single-span composite T-shaped beam.

TABLE 5: Details of single-span beams.

\begin{tabular}{lccc}
\hline Beam & Concrete of laminated layer & Stirrup ratio (\%) & Reinforcement ratio (\%) \\
\hline CCB-1 & Ordinary concrete & 0.24 & 4.86 \\
SCB-1 & SFRC & 0.24 & 4.86 \\
ZCB-1 & SFRSSC & 0.24 & 4.86 \\
\hline
\end{tabular}

TABLE 6: Details of two-span continuous beams.

\begin{tabular}{lccc}
\hline Beam & Concrete of laminated layer & Stirrup ratio (\%) & Reinforcement ratio (\%) \\
\hline CCB-2 & Ordinary concrete & 0.24 & 0.97 \\
ZCB-2 & SFRSSC & 0.24 & 0.97 \\
\hline
\end{tabular}

the same speed, rapidly reaching $100 \mathrm{~mm}$ at the beginning. After a short plateau phase, the crack heights of CCB-1 and SCB-1 reached $200 \mathrm{~mm}$ within a short time. Compared with CCB-1 and SCB-1, ZCB-1 demonstrated a slow crack height development. Finally, before the test beams failed, the cracks in the test beams CCB-1, SCB-1, and ZCB-1 reached similar heights of $247 \mathrm{~mm}, 226 \mathrm{~mm}$, and $238 \mathrm{~mm}$, respectively.

When the test beams cracked, the transverse crack widths were minimal and insufficient to pull out the steel fiber. The steel fibers together with the steel bars partially bore the tension; thus, the crack development was impeded. For ZCB-1, aside from the steel fibers, the prepressing stress generated by the self-stressing concrete could also hinder crack development. At the beginning of the test, the prepressing stress offset the tensile stress caused by the test load. Thus, the cracking stage of the test beam was postponed; as a result, the cracking load of the composite beam was improved. This crack delay phenomenon is clearly shown in Figures 13 and 14.

4.1.2. Load-Displacement Curve Analysis. The load-displacement curves of the test beams are shown in Figure 15. According to Figure 15, every load-displacement curve of 


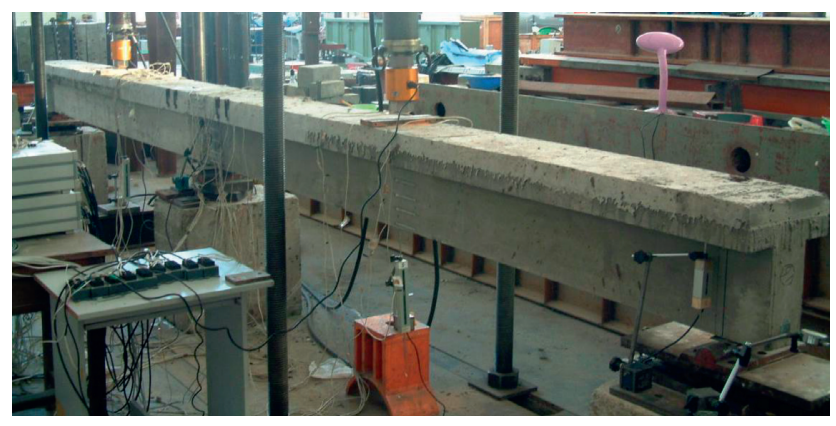

FIGURE 11: Two-span continuous composite T-shaped beam actual test setup.

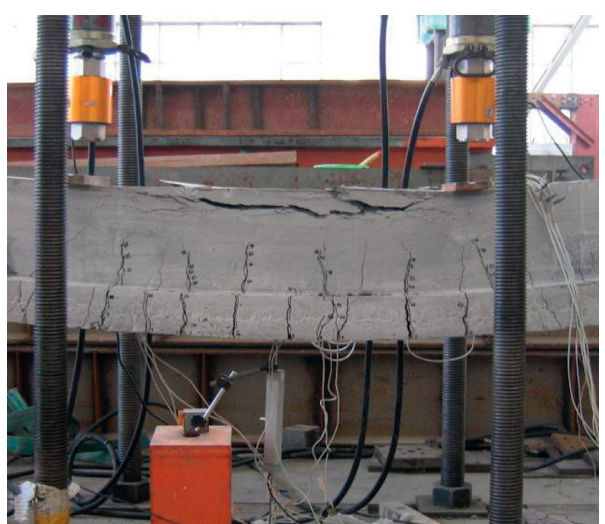

Figure 12: Cracked test beam SCB-1.

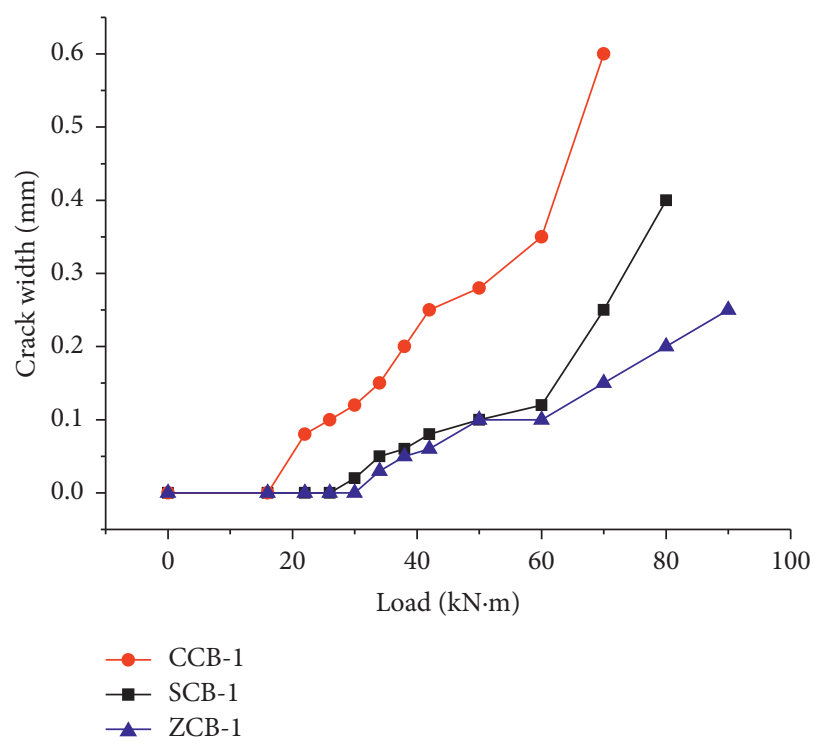

FIgURE 13: Development of crack width.

the three test beams consists of three phases: elastic, yielding, and destruction. The cracking load, yielding load, and ultimate load of every test beam were derived from Figure 15 and the test records and are shown in Table 7. As shown in Table 7, the SFRSSC laminated layer significantly improved the cracking loads of the composite beams. Compared with the cracking load of test beam CCB-1, the cracking load of SCB-1 increased by $16.83 \%$, and the cracking load of ZCB-1 increased by $50.48 \%$. 


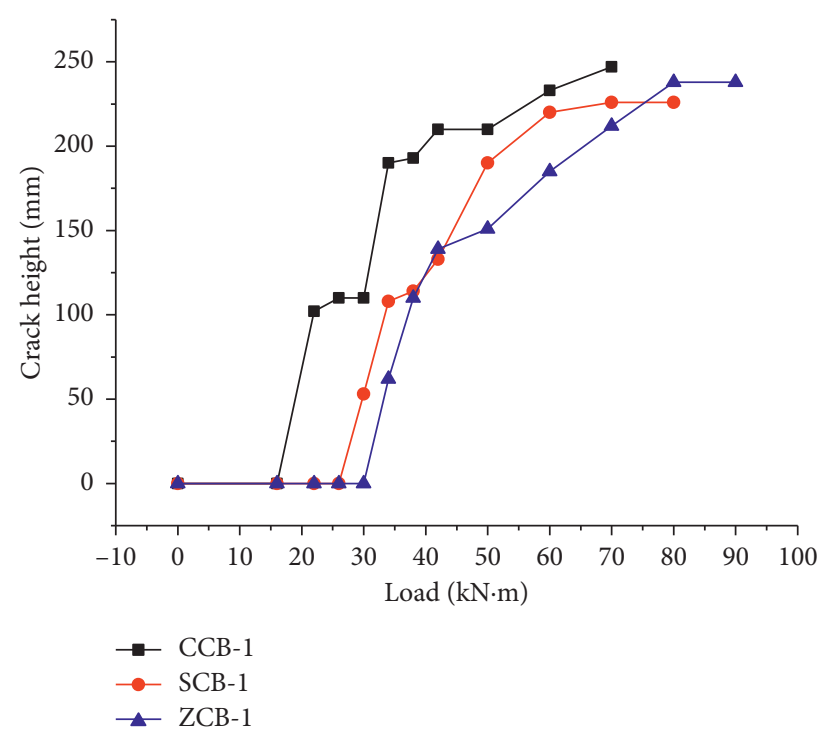

Figure 14: Development of crack height.

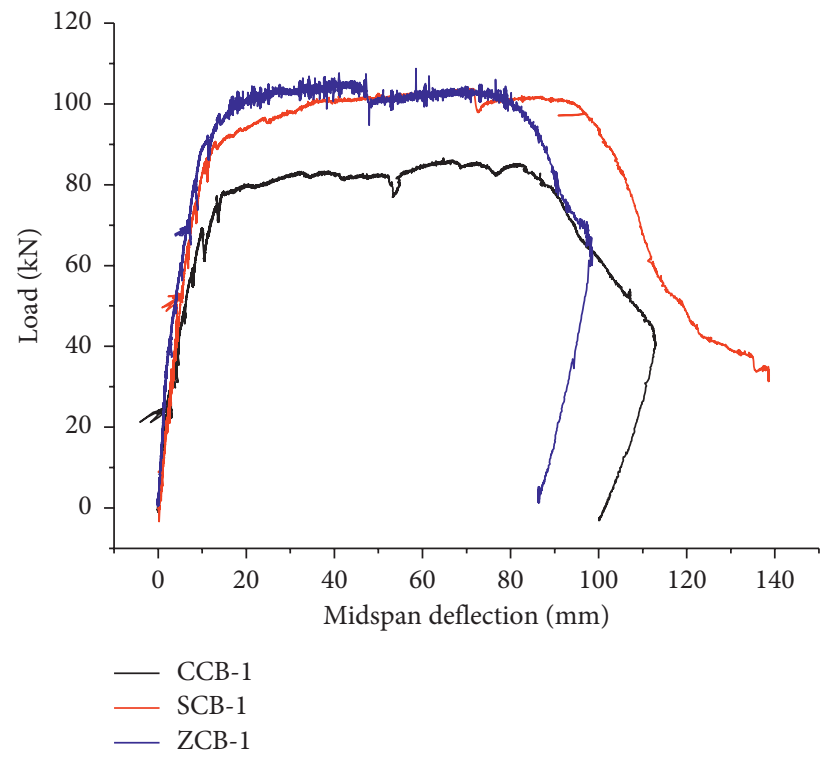

Figure 15: Load-displacement curves of the single-span composite T-shaped beams.

TABle 7: Cracking load, yielding load, and ultimate load of test beams.

\begin{tabular}{lccc}
\hline Test beams & Cracking load $(\mathrm{kN})$ & Yielding load $(\mathrm{kN})$ & Ultimate load $(\mathrm{kN})$ \\
\hline CCB-1 & 23.77 & 78.05 & 86.60 \\
SCB-1 & 27.77 & 90.45 & 104.10 \\
ZCB-1 & 35.77 & 93.63 & 105.71 \\
\hline
\end{tabular}

\subsection{Two-Span Continuous Composite T-Shaped Beam Test}

4.2.1. Load-Displacement Curve Analysis. Two test beams were loaded to simulate the flexural properties of the continuous bridge structure with SFRSSC deck pavement and investigate its flexural properties. During the test, flexural failure occurred in all test beams (Figure 16). The load- displacement curves of the test beams are presented in Figure 17. The cracking load, yielding loads at the midspan and middle support, and ultimate deflection are presented in Table 8.

The results showed that the cracking load and yielding load of ZCB-2 were $120 \%$ and $14.05 \%$ higher than those of CCB-2, respectively. The SFRSSC laminated layer 


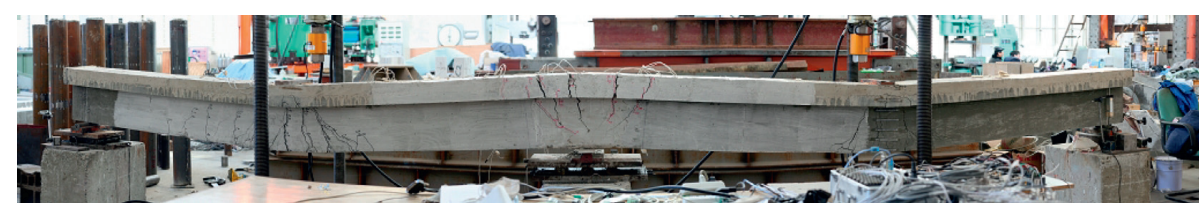

FIgURE 16: Two-span continuous composite T-shaped beams at failure.

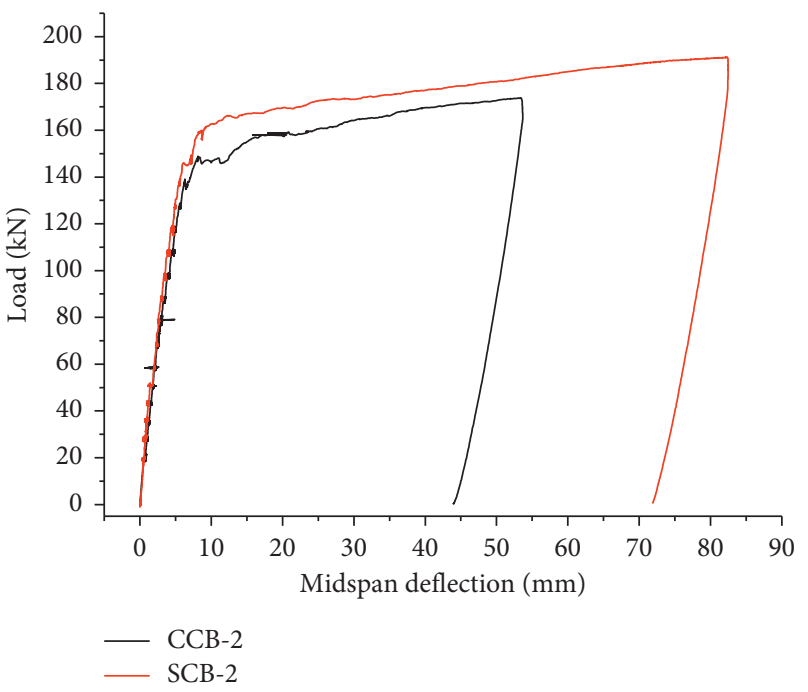

Figure 17: Load-displacement curves of the two-span beams.

TABle 8: Test results of the two-span continuous composite T-shaped beams.

\begin{tabular}{lcccc}
\hline $\begin{array}{l}\text { Test } \\
\text { beam }\end{array}$ & $\begin{array}{c}\text { Cracking load } \\
(\mathrm{kN} \cdot \mathrm{m})\end{array}$ & $\begin{array}{c}\text { Yielding load at the middle support } \\
(\mathrm{kN} \cdot \mathrm{m})\end{array}$ & $\begin{array}{c}\text { Yielding load at the midspan } \\
(\mathrm{kN} \cdot \mathrm{m})\end{array}$ & $\begin{array}{c}\text { Ultimate deflection } \\
(\mathrm{mm})\end{array}$ \\
\hline CCB-2 & 13.05 & 85.41 & 90.81 & 53.52 \\
ZCB-2 & 28.84 & 97.41 & 92.21 & 81.96 \\
\hline
\end{tabular}

significantly improved the crack resistance of the continuous T-shaped composite beams. Under the vertical load located in the adjacent span, a considerable negative moment occurred in the cross section at the intermediate support, mainly causing the cracking in the bridge. The SFRSSC used in the test exhibited good performance in terms of crack resistance because of the presence of its own self-chemical stress. Before the test even started, a certain precompressive stress generated by SFRSSC already existed in the laminated layer of ZCB-2. This precompressive stress postponed concrete cracking at the middle support when loading was initiated. Thus, the SFRSSC laminated layer enhanced the crack resistance of the test beams. After concrete cracking, the presence of steel fibers impeded the crack development in concrete, resulting in a slight improvement in the yielding load. However, the use of steel fibers is not a decisive factor on yielding load, whose increase is not significant.

For the cross section at the midspan, the SFRSSC laminated layer has minimal influence on the yielding load, as shown in Table 8 . However, with regard to deformation, the ultimate deflection in beam ZCB-2 was 53.1\% higher than that in beam CCB-2 when the test beams failed. During the experiment, the deflection in the test beams was recorded. As shown in Figure 17, in the initial stage, the deflection in ZCB-2 was significantly less than that in CCB2. As the test load increased, the deflection gap between the two test beams was decreasing. At the beginning of experiment, the precompressive stress generated by SFRSSC delayed the cracking of concrete beams; thus, the stiffness of the test beams improved. Therefore, the deflection in ZCB-2 was less than that in CCB-2 under the same load. After the concrete around the intermediate support cracked, the precompressive stress inside the SFRSSC was released. Cracks gradually fully developed. The deflection gap between ZCB-2 and CCB-2 was decreasing with the dissipation of the precompressive stress. After the test beams entered the yield stage, the steel fibers in ZCB-2 enhanced its stiffness, resulting in its ultimate deflection to be significantly higher than that in CCB-2, as shown in Figure 17. 
4.2.2. Crack Development. The crack development in each of the two test beams was observed during the test program. Figures 18-20 describe the crack width development and crack height development with respect to the test load. Figures 21 and 22 show the distributions of cracks in beams ZCB-2 and CCB-2, respectively. The development trends of the cracks around the middle support of the two-span continuous composite $\mathrm{T}$-shaped beams are similar to those of the single-span composite T-shaped beams. The precompressive stress generated by SFRSSC delayed the crack in the concrete around the middle support. Thus, the width and the height developments of the crack in beam ZCB-2 lagged behind those in beam CCB-2. As the test load increased and the maximum precompressive stress dissipated, the crack widths and crack heights of the two test beams converged.

\section{Theoretical Analysis}

With the numerical simulation results and experimental results as reference, a theoretical analysis was conducted to calculate the cracking load of the single-span composite T-shaped beams.

The basic assumptions are as follows:

(1) The deformation of the composite beams is aligned with the plane section assumption.

(2) No relative slip exists between steel and concrete.

(3) The constitutive relations for steel and concrete are known.

(4) No relative slip exists between the laminated layer and basic concrete beam.

(5) The deformation of each of the composite beams meets the minimal deformation assumption.

According to the basic assumptions, cross-sectional strains of the single-span composite T-shaped beams are continuous when subjected to bending, as shown in Figure 23. Owing to the precompressive stress in the SFRSSC laminated layer, the stress broke down in the composition plane (Figure 23). Therefore, the sectional corner $(\varphi)$ is

$$
\varphi=\frac{\sigma_{z t}+\sigma_{z 0}}{h-x} \text {. }
$$

Two equilibrium relations are apparent in the cross section of the test beams including

$$
\begin{aligned}
& \int_{0}^{x} b \sigma \mathrm{d} y+\sigma_{s}^{\prime} A_{s}^{\prime} \int_{0}^{h-x-h_{f}-h_{p}} b \sigma \mathrm{d} y+\int_{h-x-h_{f}-h_{p}}^{h-x-h_{p}} b_{f} \sigma \mathrm{d} y \\
& +\int_{h-x-h_{p}}^{h-x} b_{f}\left(\sigma-\sigma_{0}\right) \mathrm{d} y+\sigma_{s} A_{s} \\
& \quad+\int_{0}^{x} b \sigma y \mathrm{~d} y+\sigma_{s}^{\prime} A_{s}^{\prime}\left(x-a_{s}^{\prime}\right)+\int_{0}^{h-x-h_{f}-h_{p}} b \sigma y \mathrm{~d} y \\
& \quad+\int_{h-x-h_{f}-h_{p}}^{h-x-h_{p}} b_{f} \sigma y \mathrm{~d} y \\
& \quad+\int_{h-x-h_{p}}^{h-x} b_{f}\left(\sigma-\sigma_{0}\right) y \mathrm{~d} y+\sigma_{s} A_{s}\left(h-x-a_{s}\right) .
\end{aligned}
$$

The constitutive relation for concrete [27] is

$$
\sigma_{c}= \begin{cases}\sigma_{0}\left[2\left(\frac{\varepsilon_{c}}{\varepsilon_{0}}\right)-\left(\frac{\varepsilon_{c}}{\varepsilon_{0}}\right)^{2}\right], & 0 \leq \varepsilon_{c} \leq \varepsilon_{0}, \\ \sigma_{0}\left[1-0.15\left(\frac{\varepsilon-\varepsilon_{0}}{\varepsilon_{u}-\varepsilon_{0}}\right)\right], & \varepsilon_{0}<\varepsilon_{c} \leq \varepsilon_{u} .\end{cases}
$$

The constitutive relation for steel is

$$
\sigma_{s}= \begin{cases}E_{s}, & 0 \leq \varepsilon_{s} \leq \varepsilon_{y}, \\ f_{y}, & \varepsilon_{y}<\varepsilon_{s} .\end{cases}
$$

According to our previous studies [28-30], the precompressive stress of SFRSSC can been calculated by

$$
\sigma_{z 0}=\sigma_{\mathrm{rz}}+\sigma_{\mathrm{rz}, f}=\frac{\rho}{1-\rho} E_{s} C e^{-\alpha \rho}+0.368 \alpha_{t} \rho_{f} \frac{l_{f}}{d_{f}} f_{\mathrm{tk}},
$$

where $\rho$ is the reinforcement ratio of the SFRSSC laminated layer, $\alpha$ and $C$ are the parameters of SFRSSC, $\sigma_{\mathrm{rz}}$ is the precompressive stress caused by the limitation of steel, and $\sigma_{\text {rz }}, f$ is the precompressive stress caused by the limitation of steel fibers.

By substituting the parameters obtained from experiment into formula (6), the precompressive stress of SFRSSC used in this test is

$$
\sigma_{z 0}=2.17 \mathrm{MPa}
$$

With the solutions to (2)-(5), the theoretical crack moment of beam ZCB-1 can be derived as

$$
M_{\mathrm{ZCB}-1}=35.95 \mathrm{kN} \cdot \mathrm{m} \text {. }
$$

The following theoretical crack moments of CCB-1 and SCB -1 are derived by the same method:

$$
\begin{aligned}
M_{\mathrm{CCB}-1} & =16.8 \mathrm{kN} \cdot \mathrm{m}, \\
M_{\mathrm{SCB}-1} & =27.3 \mathrm{kN} \cdot \mathrm{m} .
\end{aligned}
$$

\section{Numerical Simulation}

6.1. Modeling. In this paper, a numerical simulation was performed with the software ANSYS. The numerical simulation analyses were performed for both the single-span composite T-shaped beams and the two-span continuous composite T-shaped beams. Furthermore, two additional variables were considered, namely, the precompressive stress and the length of the SFRSSC laminated layer.

The Solid65 element can be used in a 3D solid model with or without reinforcement. It was used in this study to simulate the concrete because of its capability to handle the nonlinearity of materials. The space bar element Link8 was used to simulate the reinforcement, which could withstand moments. In the nonlinear analysis, an integral model was used for the basic concrete beam, whereas a separate model was used for the concrete in the laminated layer. In all simulation beams, the bonding between concrete and steel was good, exhibiting the absence of a slip. For the model, the constitutive relation for concrete proposed by Hognestad and expressed in (4) was used, and five stress-strain 


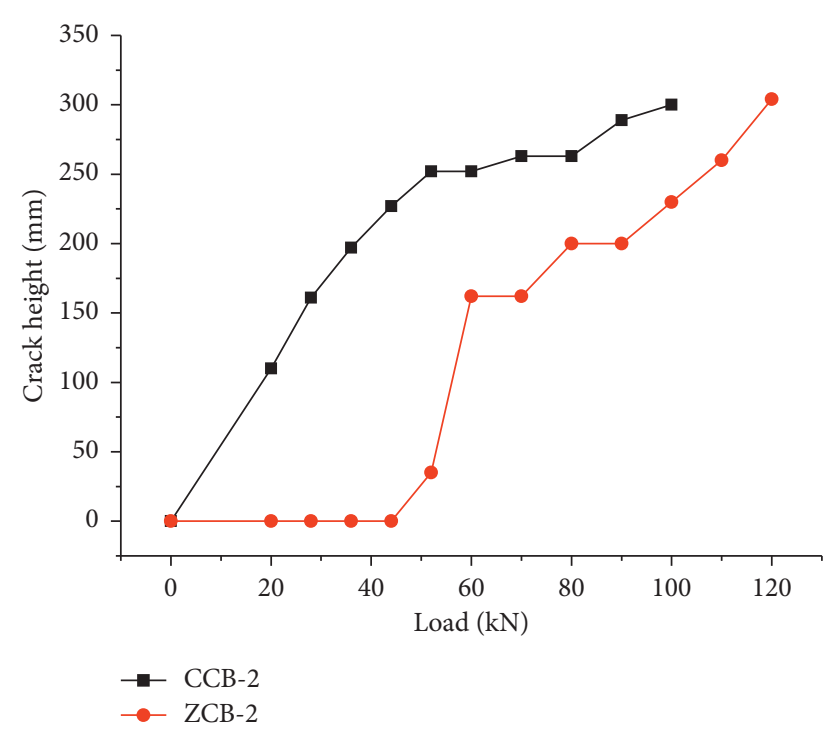

FIGURE 18: Development of crack height at the middle support.

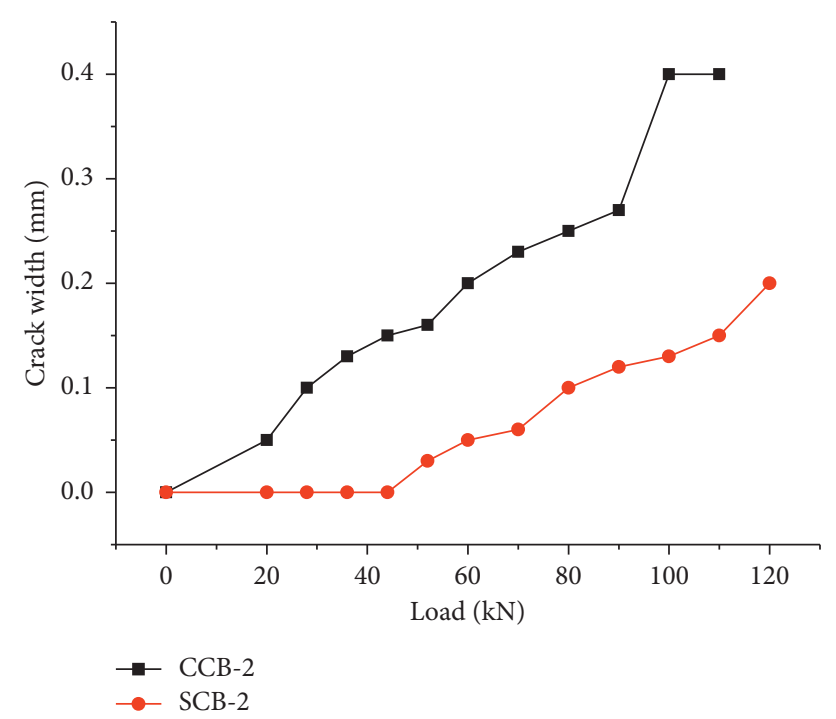

FIGURE 19: Development of crack width at the middle support.

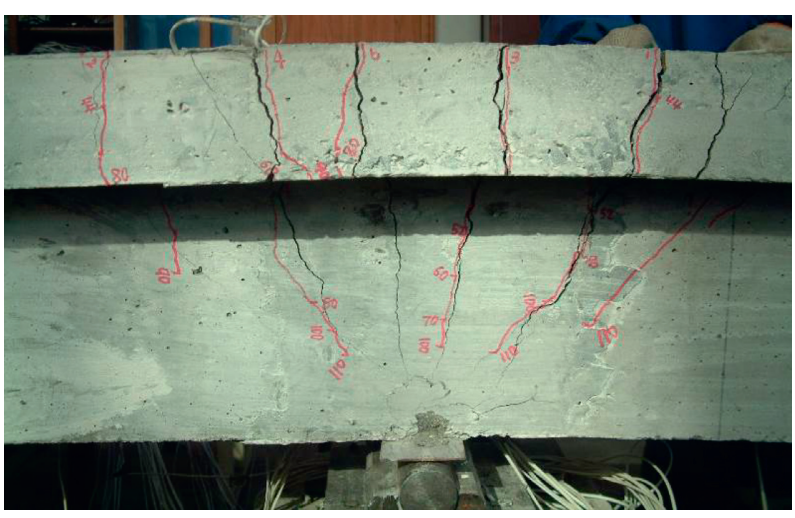

Figure 20: Cracks at the middle support. 


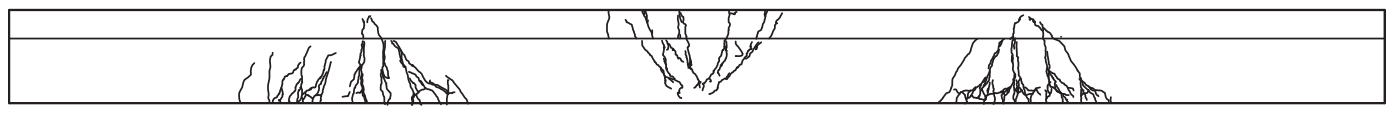

FIGURE 21: Cracks in test beam ZCB-2.

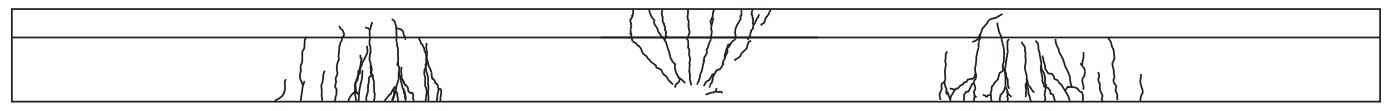

FIgURE 22: Cracks in test beam CCB-2.
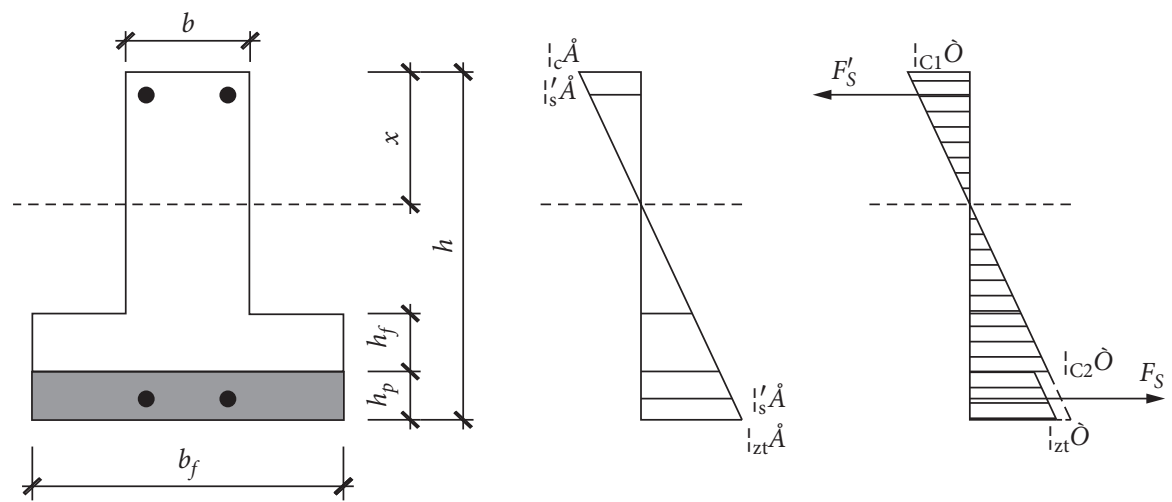

FIGURE 23: Stress and strain distributions of the single-span composite T-shaped beam.

relationship data were selected to define the curve simulated by the MISO model. Reinforcement is generally an elongated member. If the transverse shear force is disregarded, a complex stress situation will not exist. Accordingly, in this study, the constitutive relation for steel could be simulated with a bilinear isotropic hardening model (BISO). The models of the test beams are shown in Figure 24.

The thermal expansion coefficient of concrete was set to $\gamma_{c}=1.0 \times 10^{-5}\left({ }^{\circ} \mathrm{C}\right)$, and the initial temperature was $25^{\circ} \mathrm{C}$. The precompressive stress of SFRSSC was simulated by changing the temperature of concrete. The loads applied in the experiment were uniformly distributed surface loads. The force convergence criterion was used, and the convergence error was $5 \%$.

6.2. Single-Span Composite T-Shaped Beam Simulation. The load-displacement curves of the test beams were presented in Figure 25. The simulated failure processes of the three test beams were similar to those in the experimental test described in Section 4.1. The curves presented three phases: elastic phase before cracking, elastic phase after cracking, and the yield phase. The simulated deflection values were less than the experimental values because the bond slip between steel and concrete was not considered in the simulation analysis. However, it had no influence on the characteristic load values. The stress history of the middle node on the bottom surface of the test beams is shown in Figure 26. The curves indicate that stress at this point increased with an increase in the test load. When the test load reached the cracking load, the stress decreased rapidly to zero, and the concrete at this point cracked. The test load at this moment was the cracking load, which corresponds with the load where the slope initially changed in the load-displacement curves. The simulation results for cracking loads are shown in Table 9. The theoretical cracking loads are in good agreement with the experimental results and simulation results.

6.3. Different Precompressive Stresses. In the experimental test, the effects of the different precompressive stresses of SFRSSC were not considered; thus, the flexural performance of the test beams for different precompressive stress was simulated and analyzed. Given that the precompressive stress of SFRSSC is simulated by changing the temperature of concrete in this part, the considered variable temperatures were $25^{\circ} \mathrm{C}, 27^{\circ} \mathrm{C}, 29^{\circ} \mathrm{C}, 31^{\circ} \mathrm{C}, 33^{\circ} \mathrm{C}, 35^{\circ} \mathrm{C}, 37^{\circ} \mathrm{C}$, and $39^{\circ} \mathrm{C}$. The time history plot is shown in Figure 27, and the stress nephogram is shown in Figure 28. The load-displacement curves obtained are presented in Figure 29. The cracking load of each beam can be determined from Figure 29, and the influence of the variation in precompressive stress on the cracking load is shown in Figure 30.

Figure 30 shows that the cracking load of the test beams could infinitely increase with increases in the precompressive stress of SFRSSC. When the precompressive stress values ranged within 1.5-2.5 MPa, the cracking load of the composite beams was the highest; thereafter, the cracking load exhibited a decreasing trend. This result is due to the cracking load of SFRSSC being limited by the steel and the top surface of the basic beam. With the generation of the precompressive stress in SFRSSC, a certain tensile stress appears in the concrete around the top surface of the basic 


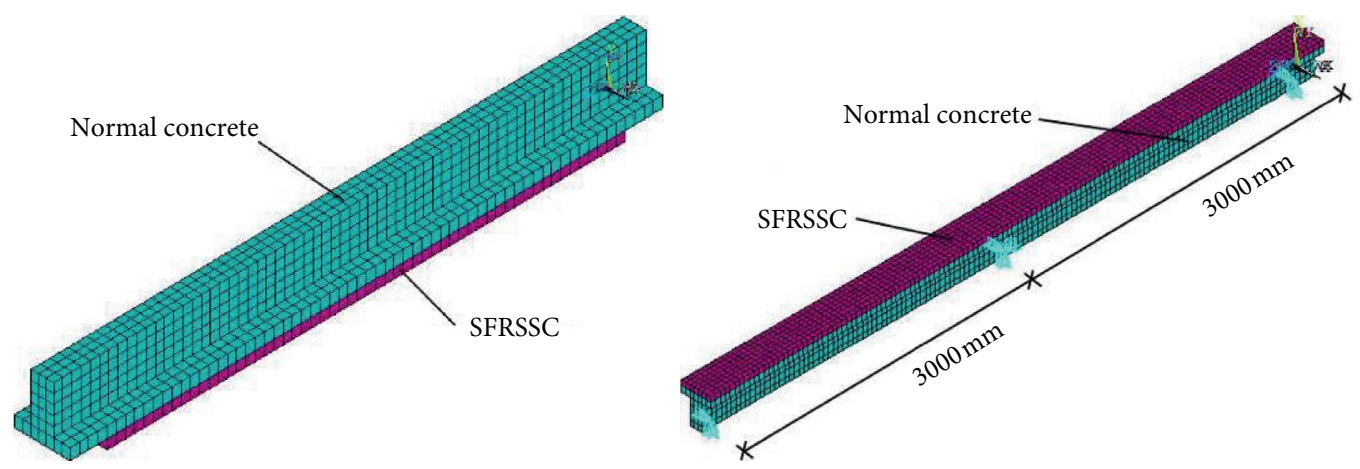

FIgURE 24: Models of test beams.

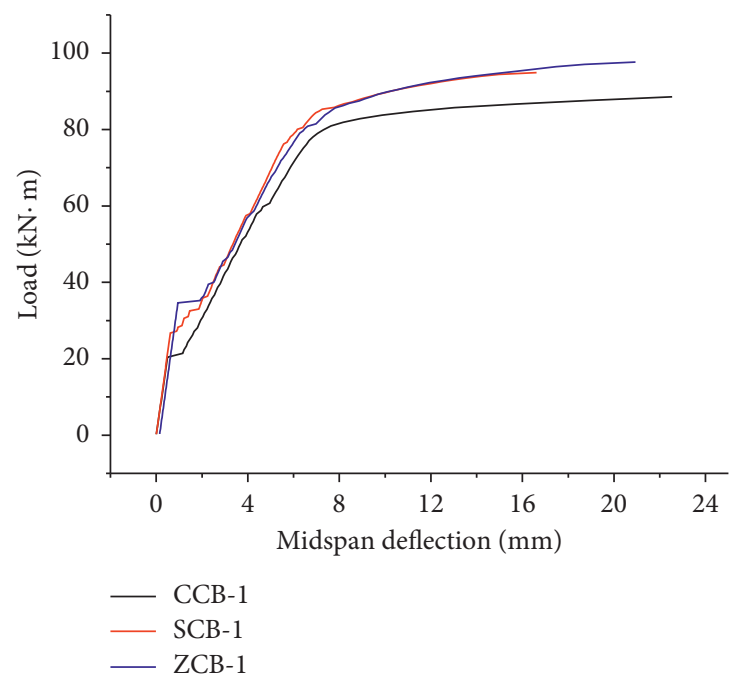

FIGURE 25: Load-displacement curves.

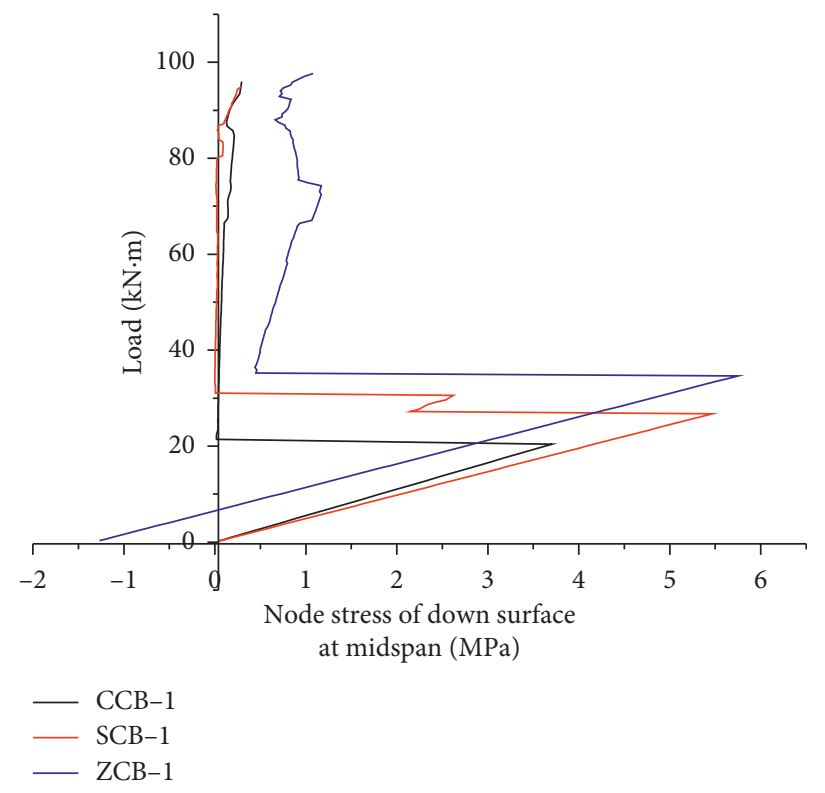

Figure 26: Stress history of the middle node on the bottom surface of the test beams. 
TABle 9: Cracking loads of the single-span composite T-shaped beams $(\mathrm{kN} \cdot \mathrm{m})$.

\begin{tabular}{lccc}
\hline Cracking load & CCB & SCB & ZCB \\
\hline Experimental results & 23.77 & 27.77 & 35.77 \\
Theoretical results & 16.85 & 27.32 & 35.95 \\
Simulation results & 20.43 & 26.76 & 34.65 \\
\hline
\end{tabular}

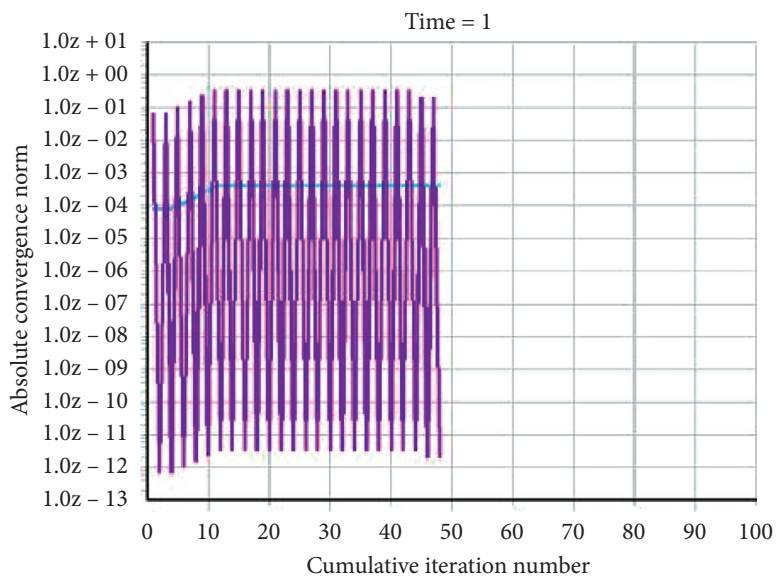

U CRIT

U L2

Figure 27: Time history plot.

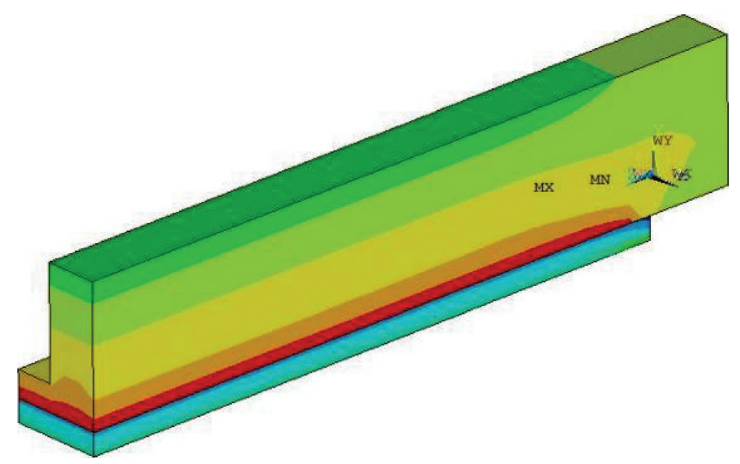

FIgURE 28: Stress nephogram.

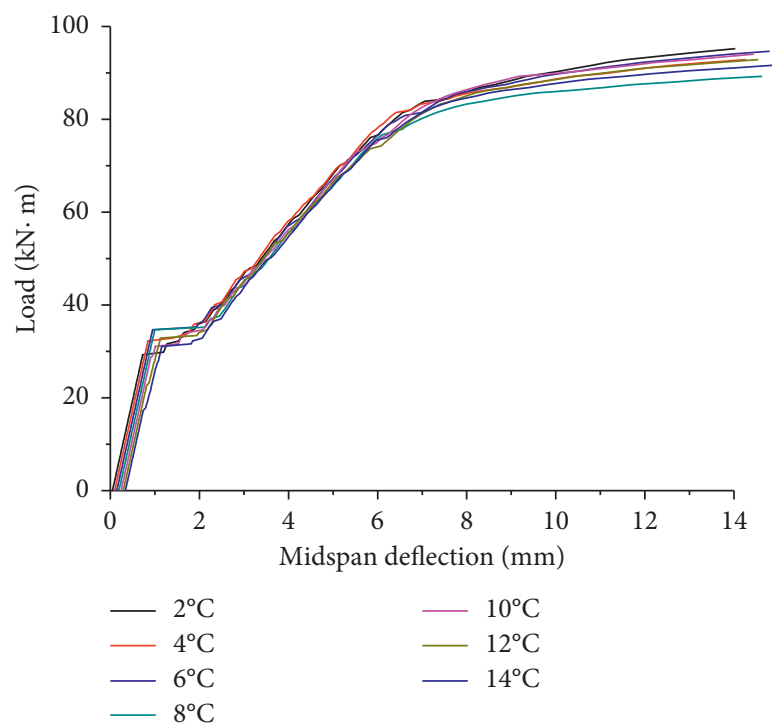

Figure 29: Load-displacement curves. 


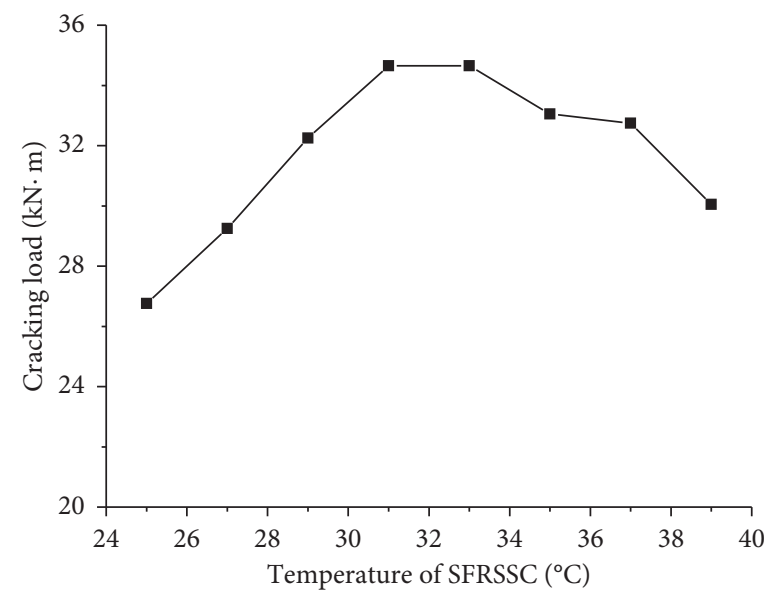

FIGURE 30: Relationship between cracking load and temperature.

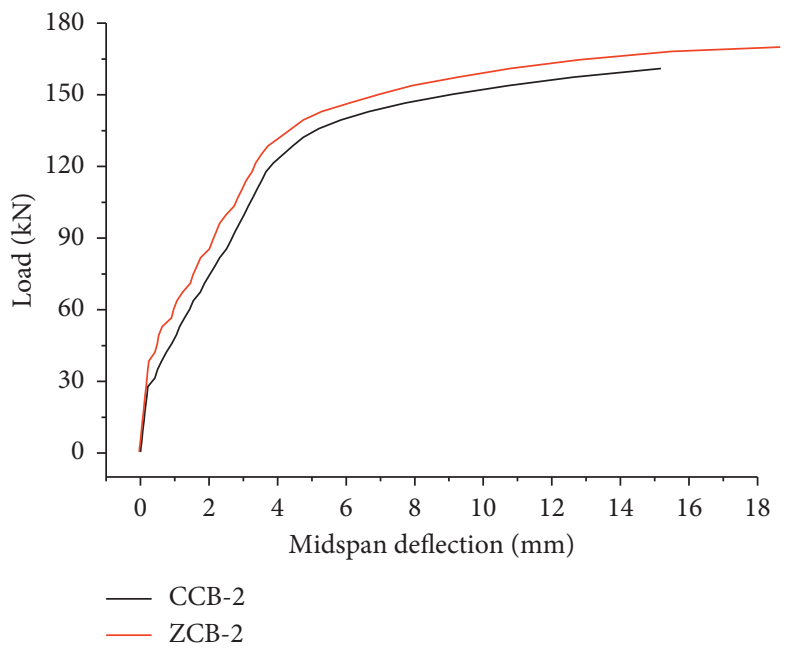

FIgURE 31: Load-displacement curves by simulation.

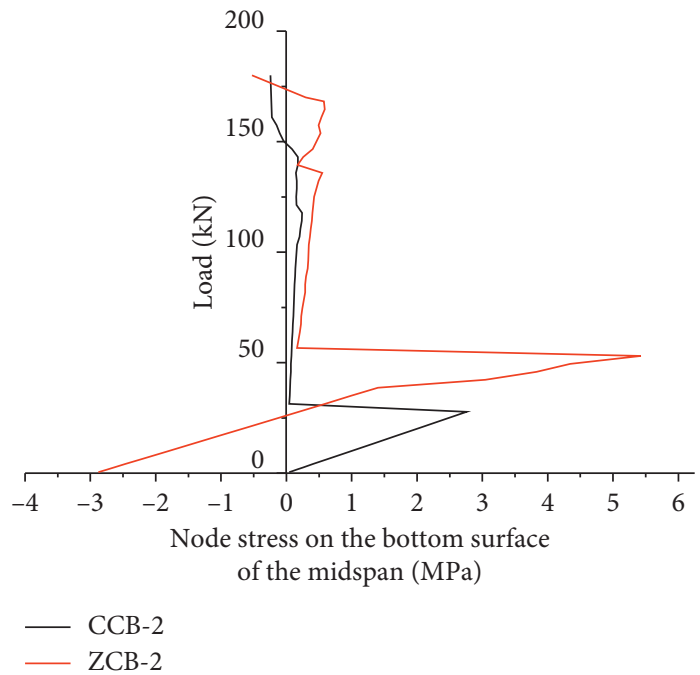

FIGURE 32: Stress history of the middle node on the top surface of the middle support. 
TABLE 10: Cracking loads of the two-span continuous composite T-shaped beams.

\begin{tabular}{lcc}
\hline Cracking load & Experimental results $(\mathrm{kN} \cdot \mathrm{m})$ & Simulation results $(\mathrm{kN} \cdot \mathrm{m})$ \\
\hline CCB-2 & 13.05 & 15.64 \\
ZCB-2 & 28.84 & 29.81 \\
\hline
\end{tabular}

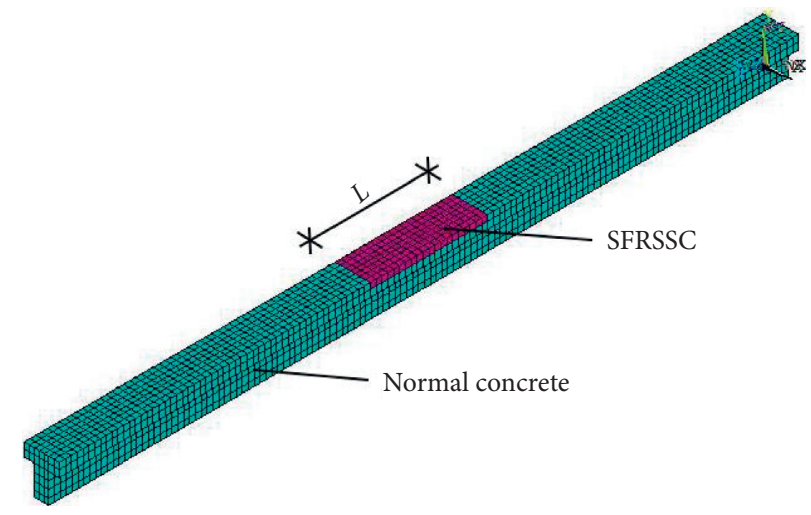

FIgURE 33: Model of condition II.

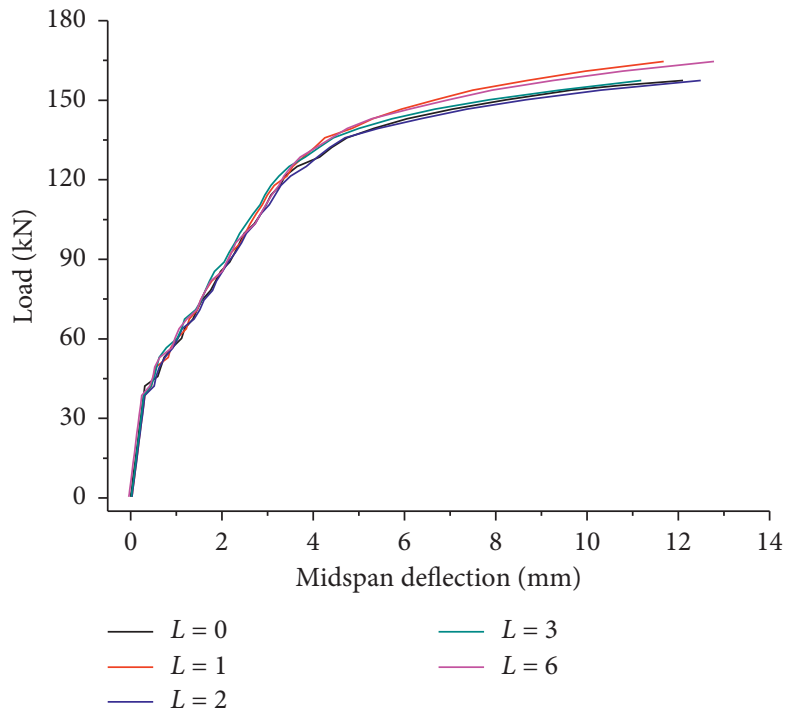

FIGURE 34: Load-displacement curves for different lengths of the SFRSSC laminated layer.

beam and increases as the precompressive stress increases. In the experiment, when the precompressive stress reached 2.5 $\mathrm{MPa}$, the concrete around the top surface of the basic beam cracked earlier than the laminated layer, causing the reduction in the cracking load.

6.4. Two-Span Continuous Composite T-Shaped Beam Simulation. The properties of materials adopted in the simulation for the two-span continuous composite T-shaped beams are the same as those described in Table 8 . The test beams' load-displacement curves obtained by simulation are displayed in Figure 31. Figure 32 shows the load-stress curves of the node on the top surface of the middle support. A certain precompressive stress evidently existed in the laminated layer of ZCB-2 before loading. The precompressive stress significantly enhanced the crack resistance of ZCB-2. The cracking loads are summarized in Table 10. Clearly, the theoretical results and the experimental results are in good agreement with the simulation results.

6.5. Influence of the Length of SFRSSC Laminated Layer on Flexural Behavior. For the two-span continuous composite T-shaped beams, the negative moment only existed at the middle support. Thus, in this study, a simulation analysis for condition II, that is, the SFRSSC was placed only in the middle support area, as shown Figure 33, was conducted. In the simulation, SFRSSC was placed around the middle support, with the support as the center. Normal concrete was 


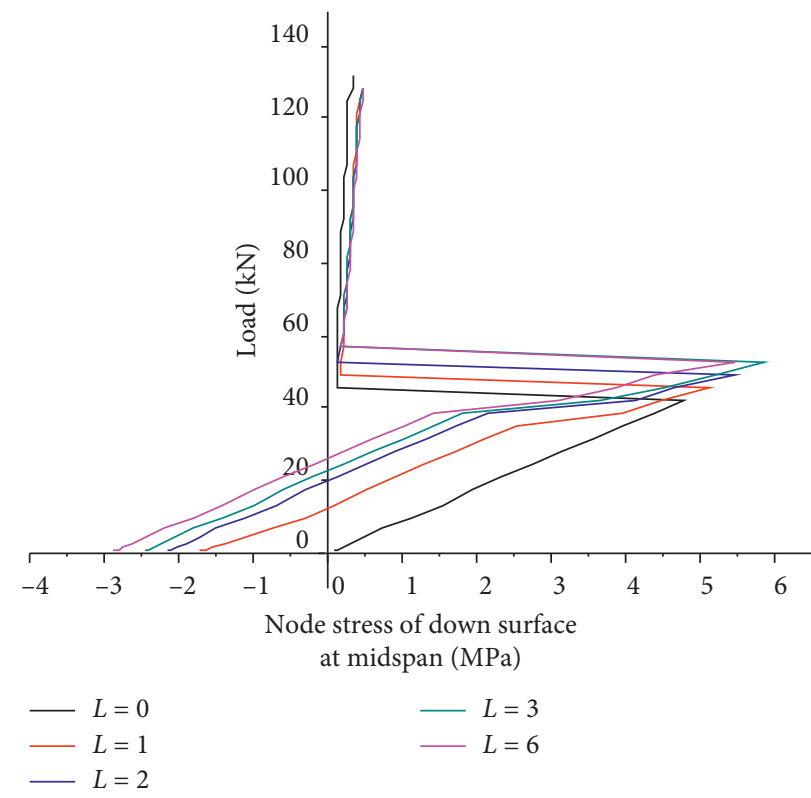

FIGURE 35: Stress history of the middle node on the top surface of the middle support.

TABLE 11: Cracking loads and precompressive stresses.

\begin{tabular}{lccccc}
\hline $\mathrm{L}(\mathrm{m})$ & 0 & 1 & 2 & 3 & 6 \\
\hline$M_{\mathrm{cr}}(\mathrm{kN} \cdot \mathrm{m})$ & 23.74 & 25.76 & 27.79 & 28.87 & 29.81 \\
$\sigma_{z 0}(\mathrm{MPa})$ & 0 & -1.84 & -2.22 & -2.53 & -2.92 \\
\hline
\end{tabular}

poured into the remainder of the laminated layer. The lengths of SFRSSC were $1,2,3$, and $6 \mathrm{~m}$.

The test beams' load-displacement curves obtained by simulation are displayed in Figure 34. Figure 35 shows the load-stress curves of the node on the top surface of the middle support. The cracking loads $\left(M_{\mathrm{cr}}\right)$ and precompressive stresses $\left(\sigma_{z 0}\right)$ on the top surface of the beams were recorded and are summarized in Table 11. Figure 34 shows that the length of the SFRSSC laminated layer had minimal influences on the yield strengths and ultimate strengths of the test beams. Table 11 shows that the precompressive stress and cracking load decreased with a decrease in the length of the SFRSSC laminated layer. However, the cracking loads of the test beams were similar when the length of the SFRSSC laminated layer was 6, 3, or $2 \mathrm{~m}$. Considering the material consumption and cracking resistance, the reasonable length of the SFRSSC laminated layer, as indicated by $L$ in Figure 33, is $1 / 3$ to $1 / 2$ of the beam span.

\section{Conclusions}

(1) SFRSSC significantly improves the cracking load of two-span continuous composite T-shaped beams. Although the height of the laminated layer is only $14 \%$ of the height of the test beam, it allowed for the 2.2-fold increase in the cracking load in the negative moment area.

(2) A calculation method for the cracking load of the concrete composite beams with a SFRSSC laminated layer is established. The calculation or theoretical results are in good agreement with the experimental results.

(3) For the single-span composite T-shaped beams, the cracking load is desirable when the precompressive stress of SFRSSC ranges within 1.5-2.5 MPa.

(4) For the two-span continuous T-shaped composite beams, the reasonable length of the SFRSSC laminated layer is $1 / 3-1 / 2$ of the beam span.

(5) The SFRSSC laminated layer has minimal influences on yielding load and ultimate load.

\section{Data Availability}

The data used to support the findings of this study are included within the article.

\section{Conflicts of Interest}

The author declares that there are no conflicts of interest regarding the publication of this paper.

\section{Acknowledgments}

This research work was financially supported by National Natural Science Foundation of China (Grants nos. 41430642, 41627801, and 51108207) and China Postdoctoral Science Foundation (Grant no. 2015M581403).

\section{References}

[1] L. Fan, Bridge Engineering, China Communications Press, Beijing, China, 2011.

[2] M. Jing, "Research on crack deterioration of long-span bridges deck pavement," Master's Thesis, Southeast University, Nanjing, China, 2005. 
[3] J. Wang, "Method and research on deterioration of steel deck gussasphalt concrete pavement," Master's Thesis, Southeast University, Nanjing, China, 2005.

[4] L. Zhang, "Research on deterioration of jiang yin bridge deck pavement," Master's Thesis, Southeast University, Nanjing, China, 2004.

[5] J. Wang, "Causes analysis of early distresses and design method of asphalt concrete pavement for concrete bridge deck," Master's Thesis, Dalian University of Technology, Dalian, China, 2003.

[6] K. Habel, J.-P. Charron, E. Denarié, and E. Brühwiler, "Autogenous deformations and viscoelasticity of UHPFRC in structures part I: experimental results," Magazine of Concrete Research, vol. 58, no. 3, pp. 135-145, 2006.

[7] K. Habel, E. Denarié, and E. Brühwiler, "Time dependent behavior of elements combining ultra-high performance fiber reinforced concretes (UHPFRC) and reinforced concrete," Materials and Structures, vol. 39, no. 5, pp. 557-569, 2006.

[8] K. A. Harries and J. Moses, "Effect on superstructure stress of replacing a composite RC bridge deck with a GFRP deck," Journal of Bridge Engineering, vol. 12, no. 3, pp. 394-398, 2007.

[9] K. Coogler, K. A. Harries, B. Wan, D. C. Rizos, and M. F. Petrou, "Critical evaluation of strain measurements in glass fiber-reinforced polymer bridge decks," Journal of Bridge Engineering, vol. 10, no. 6, pp. 704-712, 2005.

[10] K. Habel, M. Viviani, E. Denarié, and E. Brühwiler, "Development of the mechanical properties of an ultra-high performance fiber reinforced concrete (UHPFRC)," Cement and Concrete Research, vol. 36, no. 7, pp. 1362-1370, 2006.

[11] B. Francesco, C. Antonio, and O. Luciano, "Numerical and analytical modeling of concrete beams with steel, FRP and hybrid FRP-steel reinforcements," Composite Structures, vol. 140, pp. 53-65, 2016.

[12] G. Kaur, S. P. Singh, and S. K Kaushik, "Mean and design fatigue lives of SFRC containing cement-based materials," Magazine of Concrete Research, vol. 68, no. 7, pp. 325-338, 2016.

[13] D.-Y. Yoo, N. Banthia, and Y.-S. Yoon, "Flexural behavior of ultra-high-performance fiber-reinforced concrete beams reinforced with GFRP and steel rebars," Engineering Structures, vol. 111, pp. 246-262, 2016.

[14] N. P. B. Tan, L. H. Keung, W. H. Choi et al., "Silica-based selfhealing microcapsules for self-repair in concrete," Journal of Applied Polymer Science, vol. 133, no. 12, 2016.

[15] H. Gurdián, E. García-Alcocel, F. Baeza-Brotons, P. Garcés, and E. Zornoza, "Corrosion behavior of steel reinforcement in concrete with recycled aggregates, fly ash and spent cracking catalyst," Materials, vol. 7, no. 4, pp. 3176-3197, 2014.

[16] R. Siddique, K. Kapoor, E.-H. Kadri, and R. Bennacer, "Effect of polyester fibres on the compressive strength and abrasion resistance of HVFA concrete," Construction and Building Materials, vol. 29, pp. 270-278, 2012.

[17] K. Habel and P. Gauvreau, "Response of ultra-high performance fiber reinforced concrete (UHPFRC) to impact and static loading," Cement and Concrete Composites, vol. 30, no. 10, pp. 938-946, 2008.

[18] P. Zhang, Y. Zheng, K. Wang, and K. Zhang, "Combined influence of nano-CaCO3 and polyvinyl alcohol fibers on fresh and mechanical performance of concrete incorporating fly ash," Structural Concrete, vol. 21, no. 2, 2019.

[19] P. Zhang, Y. Ling, J. Wang, and Y. Shi, "Bending resistance of PVA fiber reinforced cementitious composites containing nano- $\mathrm{SiO}_{2}$," Nanotechnology Reviews, vol. 8 , no. 1 , pp. 690-698, 2019.
[20] P. Zhang, L. Kang, J. Wang et al., "Mechanical properties and explosive spalling behavior of steel-fiber-reinforced concrete exposed to high temperature-a review," Applied Sciences, vol. 10 , no. 7 , p. 2324,2020 .

[21] J. Shan, Study and application in high performance concrete for bridge deck overlays, Ph.D. Thesis, Wuhan University of Technology, Wuhan, China, 2006.

[22] C. K. Y. Leung, Y. N. Cheung, and J. Zhang, "Fatigue enhancement of concrete beam with ECC layer," Cement and Concrete Research, vol. 37, no. 5, pp. 743-750, 2007.

[23] J. Zhang, C. K. Y. Leung, and Y. N. Cheung, "Flexural performance of layered ECC-concrete composite beam," Composites Science and Technology, vol. 66, no. 11, pp. 1501-1512, 2006.

[24] L. Luo, Construction technology of SFRPC bridge deck pavement, Ph.D. Thesis, South China University of Technology, Guangzhou, China, 2002.

[25] B. Wan, D. C. Rizos, M. F. Petrou, and K. A. Harries, "Computer simulations and parametric studies of GFRP bridge deck systems," Composite Structures, vol. 69, no. 1, pp. 103-115, 2005.

[26] W. C. Tang, R. V. Balendran, A. Nadeem, and H. Y. Leung, "Flexural strengthening of reinforced lightweight polystyrene aggregate concrete beams with near-surface mounted GFRP bars," Building and Environment, vol. 41, no. 10, pp. 1381-1393, 2006.

[27] Z. Guo, Concrete Strength and Constitutive Relation-Principles and Applications, China Industry Press, Beijing, China, 2004.

[28] R. V. Balendran, F. P. Zhou, A. Nadeem, and A. Y. T. Leung, "Influence of steel fibres on strength and ductility of normal and lightweight high strength concrete," Building and Environment, vol. 37, no. 12, pp. 1361-1367, 2002.

[29] L. Carin, W. Roberts, and W. S. Guirola, "Strength and performance of fiber-reinforced concrete composite slabs," Journal of Structural Engineering, vol. 130, no. 3, pp. 520-528, 2004.

[30] C. Huang, Fiber Reinforced Concrete Structures, Beijing Machinery Industry Press, Beijing, China, 2004. 